\title{
The study of clinical profile and vitamin B 12 in dengue fever patients
}

\author{
Mamatha Tittamegalapalya Ramalingaiah', Jeetendra Kumar Jogihalli Mood², \\ Satyanarayana Narayanashetty ${ }^{3}$, Rashmi Madappa Bhuvaneshappa ${ }^{4}$
}

${ }^{1}$ Assistant Professor, ${ }^{2}$ Professor, ${ }^{3}$ Professor and Head, ${ }^{4}$ Junior Resident, Department of General Medicine, ESI Post Graduate Institute of Medical Science and Research, Rajajinagar, Bangalore, Karnataka, India

Background: Dengue is an acute infectious febrile illness characterised by thrombocytopenia and platelet dysfunction leading to bleeding manifestations. Vitamin B12 is required for platelet production in the bone marrow. So, deficiency of vitamin B12 in dengue patients can have severe thrombocytopenia. Aims and Objective: Study was aimed to know the clinical profile of dengue fever patients and to correlate serum vitamin B12 level with severity of thrombocytopenia, platelet transfusion and duration of hospital stay. Materials and Methods: This observational study was done on dengue patients for period of 3 months January 2020 to March 2020. Confirmed cases of dengue fever with NS 1 Ag positive \& Ig M antibody positive were included in the study. Patient with sepsis, underlying malignancy, autoimmune disorder, hematological disorder, drugs causing thrombocytopenia were excluded from the study. Appropriate statistical methods were applied. Results: Total 50 subjects were included. Majority of subjects were in the age group 31 to 40 years. $50 \%$ were males and females respectively. Most common clinical feature was fever and bleeding manifestations. Mean Vitamin B12 was significantly lower among those with severe thrombocytopenia and highest among those with no thrombocytopenia., there was significant difference in mean Platelet transfusion and duration of hospital stay with respect to severity of Platelet count. Conclusion: Dengue fever patients with vitamin B 12 deficiency had moderate to severe thrombocytopenia and more bleeding manifestations. Those patients required more platelet transfusion and increased duration of hospital stay.
Access this article online

Website:

http://nepjol.info/index.php/AJMS

DOI: 10.3126/ajms.v12i7.36311

E-ISSN: 2091-0576

P-ISSN: 2467-9100

Copyright (c) 2021 Asian Journal of Medical Sciences

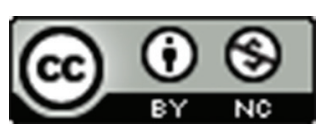

This work is licensed under a Creative Commons Attribution-NonCommercial 4.0 International License.

Key words: Dengue; Vitamin B12; Thrombocytopenia

\section{INTRODUCTION}

Dengue is a mosquito-borne viral disease that has rapidly spread in all regions of $\mathrm{WHO}$ in recent years. ${ }^{1}$ The incidence of dengue has grown dramatically around the world in recent decades. A vast majority of cases are asymptomatic or mild and self-managed, and hence the actual numbers of dengue cases are under-reported. Many cases are also misdiagnosed as other febrile illnesses. ${ }^{2}$ The virus is transmitted to humans through the bites of infected female mosquitoes, primarily the Aedes aegypti mosquito. It is caused by a virus of the Flaviviridae family and there are four distinct serotypes of the virus that cause dengue (DENV-1, DENV-2, DENV-3 and DENV-4), ${ }^{3,4}$ It causes a wide spectrum of disease. This can range from sub clinical disease (people may not know they are even infected) to severe flu-like symptoms in those infected. Although less common, some people develop severe dengue, which can be associated with severe bleeding, organ impairment and/or plasma leakage. Severe dengue has a higher risk of death when not managed appropriately. Dengue fever is a severe flu-like infection that involves individuals of all age groups (infants, children, adolescents, and adults). ${ }^{5}$ Transmission among human beings occurs by the mosquito Aedes aegypti and chiefly occurs during the rainy season. ${ }^{6}$ The proposed etiologies for dengue virus infection are Viral replication, primarily in macrophages, direct skin infection by the virus, immunological and chemical-mediated mechanism induced by host-viral interaction. ${ }^{7}$ Thrombocytopenia may be related to alterations in megakaryocytopoiesis, manifested by 
infection of human haematopoietic cells and compromised progenitor cell growth. This may cause platelet dysfunction, damage, or depletion, leading to significant hemorrhages. ${ }^{8,9}$ In 2009, the new World Health Organization (WHO) dengue case classification - dengue/severe dengue (D/SD) - was introduced, replacing the 1997 WHO dengue case classification: dengue fever/dengue haemorrhagic fever/ dengue shock syndrome (DF/DHF/DSS). ${ }^{10}$ Expanded Dengue syndrome is a term announced by the WHO in 2011 to cover the uncommon expressions of dengue involving severe damage to the liver, kidneys, bone marrow, heart, or brain. ${ }^{11}$

Dengue symptoms is characterized by a biphasic, highgrade fever lasting for 3 days to 1 week. ${ }^{12,13}$ Other symptoms are retrobulbar pain, rashes, myalgia and painful joint, metallic taste, appetite loss, diarrhea, vomiting, and abdomen pain. Dengue is also known as break-bone fever because of the associated myalgia and pain in joints. ${ }^{14}$ Flushing, a characteristic feature is commonly observed on the face, neck, and chest. The most common hemorrhagic manifestation are epistaxis, bleeding gums, skin hemorrhages and gastrointestinal hemorrhages. ${ }^{15}$

Vitamin B 12 deficiency causes anemia, leukopenia and thrombocytopenia. Approximately 10 percent of patients with symptomatic B12 (cobalamin) deficiency have significant thrombocytopenia. ${ }^{16}$ Patients with vitamin B 12 deficiency infected with dengue can develop severe thrombocytopenia with bleeding manifestations. There are no sufficient studies associating severe dengue viral infection with Vitamin B12 deficiency. So, this study has been taken.

\section{Aims and objectives of the study}

1 To study the clinical profile of dengue fever patients

2 Correlation between Vitamin B12 deficiency and severity of thrombocytopenia in dengue fever patients

3 Correlation between Vitamin B12 level and duration of hospital stay in dengue fever patients.

4 Correlation between Vitamin B12 level and platelet transfusion in dengue fever patients

\section{MATERIALS AND METHODS}

We conducted observational study on dengue patients of sample size 50 admitted in general medicine ward for period of 3 months January 2020 to March 2020, ESI PGIMSR Rajajinagar, Bangalore. Demographic data, history, clinical examination was recorded in the study proforma. A thorough clinical evaluation was carried out and recorded in the protocol. Relevant laboratory investigations was sent and results are tabulated. Approval was obtained from the Institutional Ethics Committee prior to the commencement of the study.
Inclusion criteria

1) Patients with aged more than 18 years.

2) Confirmed cases of dengue fever with NS $1 \mathrm{Ag}$ positive and Ig M antibody positive

3) Patients giving consent for the study

\section{Exclusion criteria}

1) Patient with sepsis

2) Underlying malignancy, on chemotherapy, autoimmune disorder,

3) Hematological disorder, drugs causing thrombocytopenia

For the study purpose, we defined the case definition as below

\section{Case definition}

- Dengue fever positive $=$ NS 1 antigen positive, $\operatorname{Ig}$ M antibody positive

- Thrombocytopenia - Platelet less than 1.5 lac

- Mild thrombocytopenia - 1 to 1.5 lac

- Moderate thrombocytopenia - 50,000 to 1 lac

- Severe thrombocytopenia - less than 50,000

- Vitamin B12 deficiency - less than 190pg/ml

- Normal Vitamin B12 - 190pg/ml to $950 \mathrm{pg} / \mathrm{ml}$

\section{Statistical analysis}

Data was entered into Microsoft excel data sheet and was analyzed using SPSS 22 version software. Categorical data was represented in the form of Frequencies and proportions. Chi-square test was used as test of significance for qualitative data. Continuous data was represented as mean and standard deviation. Independent $t$ test was used as test of significance to identify the mean difference between two quantitative variables.

$\mathrm{p}$ value (Probability that the result is true) of $<0.05$ was considered as statistically significant after assuming all the rules of statistical tests.

\section{RESULTS}

Profile of subjects with Dengue fever in the study Mean age of subjects was $39.20 \pm 13.77$ years. Majority of subjects were in the age group 31 to 40 years (26\%), 50\% were males and females respectively.

In the study $78 \%$ were $\mathrm{NS} 1+$ ve and $22 \%$ were $\operatorname{IgM}+$ ve. Most common clinical feature was fever in $70 \% .48 \%$ had bleeding manifestations. Most common bleeding manifestation was bleeding gums $28 \%$ and $16 \%$ had Polyserositis (Table 1).

$$
\chi^{2}=31.1, \mathrm{df}=3, \mathrm{p}<0.001 *
$$

Asian Journal of Medical Sciences | Jul 2021 | Vol 12 | Issue 7 


\begin{tabular}{|c|c|c|c|}
\hline & & Count & $\%$ \\
\hline Dengue & $\lg M+v e$ & 11 & $22.0 \%$ \\
\hline Profile & NS 1+ve & 39 & $78.0 \%$ \\
\hline Clinical & Fever & 35 & $70.0 \%$ \\
\hline \multirow[t]{5}{*}{ Features } & Fever, Cough & 2 & $4.0 \%$ \\
\hline & Fever, myalgia & 6 & $12.0 \%$ \\
\hline & Fever, Retro bulbar eye pain & 1 & $2.0 \%$ \\
\hline & Fever, Vomiting & 1 & $2.0 \%$ \\
\hline & Fever, arthralgia & 5 & $10.0 \%$ \\
\hline Bleeding & Nil & 26 & $52.0 \%$ \\
\hline \multirow[t]{7}{*}{ Manifestations } & Bleeding gums & 14 & $28.0 \%$ \\
\hline & Epistaxis & 1 & $2.0 \%$ \\
\hline & Hematuria & 1 & $2.0 \%$ \\
\hline & Malena & 3 & $6.0 \%$ \\
\hline & Petechiae & 3 & $6.0 \%$ \\
\hline & Petechiae, Bleeding gums & 1 & $2.0 \%$ \\
\hline & Petechiae, Malena & 1 & $2.0 \%$ \\
\hline \multirow[t]{2}{*}{ Polyserositis } & Absent & 42 & $84.0 \%$ \\
\hline & Present & 8 & $16.0 \%$ \\
\hline
\end{tabular}

In the study, among subjects with no thrombocytopenia and mild thrombocytopenia, 100\% had normal Vitamin B12 levels. Among those with Moderate thrombocytopenia, 62.5\% had Vitamin B12 Deficiency and 37.5\% had normal Vitamin B12 levels and among those with severe thrombocytopenia, 94.4\% had Vitamin B12 deficiency and 5.6\% had normal Vitamin B12 levels. There was significant association between platelet count and Vitamin B12 levels (Table 2).

In our study there was significant positive correlation between Vitamin B12 and Platelet count that is with decrease in platelet count there was decrease in Vitamin B12 levels and vice versa (Figure 1).

In our study there was significant negative correlation between Vitamin B12 and Platelet count that is with decrease in B12 levels there was increase in duration of hospital stay and vice versa (Figure 2).

In our study there was significant negative correlation between Vitamin B12 and Platelet transfusion that is with decrease in B12 levels there was increase in need of platelet transfusion and vice versa (Figure 3).

In the study among subjects with Vitamin B12 deficiency mean platelet count was $43037.0 \pm 27732.9$ and among subjects with normal Vitamin B12 was 164434.8 \pm 92198.8 . There was significant difference in mean platelet count among those with and without B12 deficiency (Table 3).

In our study there was significant difference in mean Vitamin B12 levels with respect to Severity of Thrombocytopenia. Mean Vitamin B12 was significantly lower among those with Severe Thrombocytopenia and highest among those with No Thrombocytopenia.

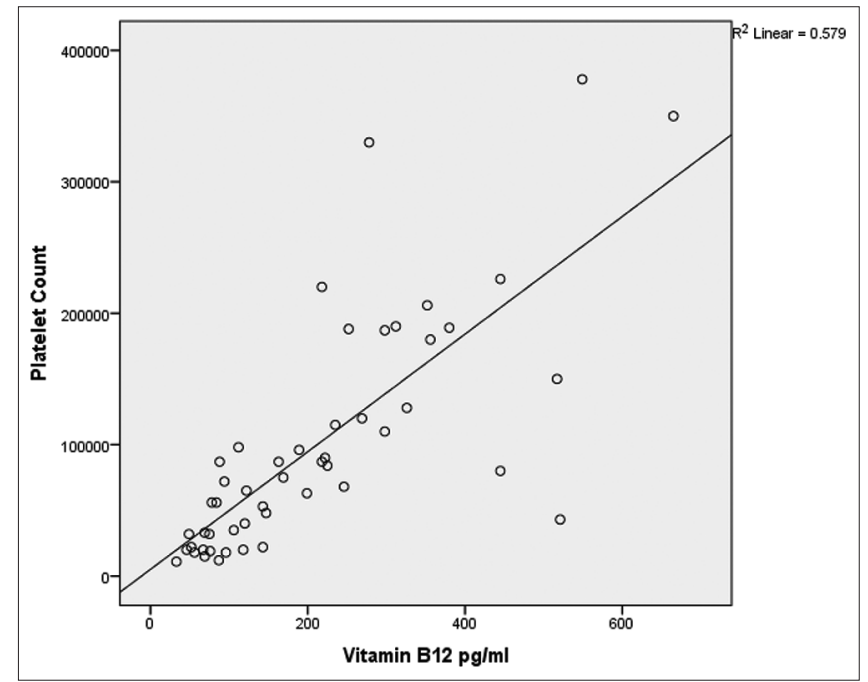

Figure 1: Scatter plot showing Positive correlation between Vitamin B12 and Platelet count

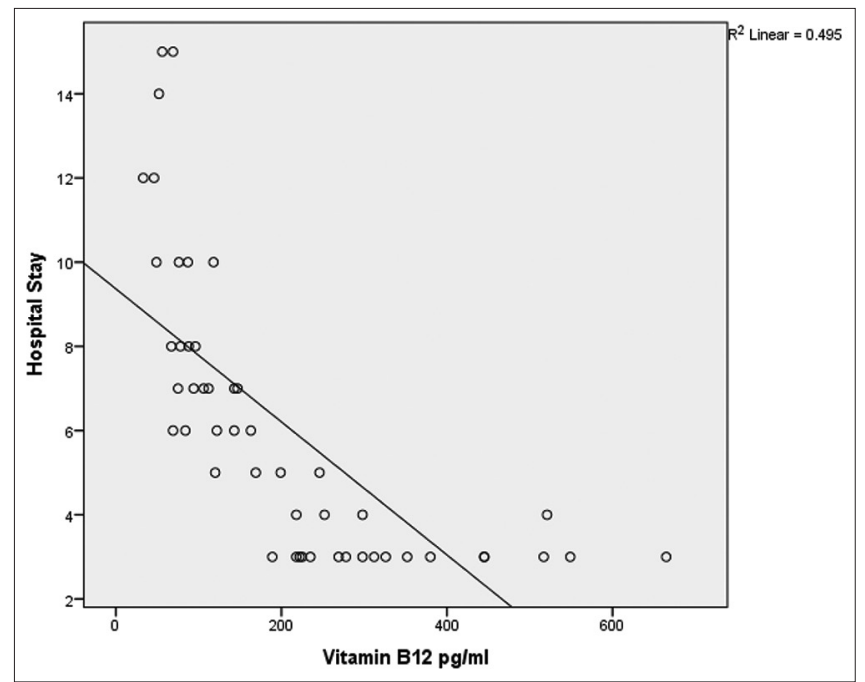

Figure 2: Scatter Plot showing Correlation between Vitamin B12 and Duration of Hospital Stay

Similarly, there was significant difference in mean Platelet transfusion and duration of hospital stay with respect to Severity of Platelet count (Table 4).

\section{DISCUSSION}

Vitamin B12 acts as a co factor during synthesis phase of the cells in bone marrow. So, Vitamin B12 deficiency causes thrombocytopenia. Serum Vitamin B12 levels are not frequently tested in patients being treated for thrombocytopenia secondary to spectrum of dengue viral infection.

In our study out of 50 patients, 78\% (39) patients had dengue NS1 antigen +ve and 22\% (11) patients had dengue IgM +ve. Most common clinical feature was fever followed 
Table 2: Association between Vitamin B12 and Platelet count

\begin{tabular}{|c|c|c|c|c|c|}
\hline & & \multicolumn{4}{|c|}{ Vitamin B12 pg/ml } \\
\hline & & \multicolumn{2}{|c|}{$\begin{array}{c}\text { Vitamin B12 deficiency } \\
(<190 \mathrm{pg} / \mathrm{ml})\end{array}$} & \multicolumn{2}{|c|}{$\begin{array}{c}\text { Normal Vitamin B12 }(190 \mathrm{pg} / \mathrm{m} \\
\text { to } 950 \mathrm{pg} / \mathrm{ml})\end{array}$} \\
\hline & & Count & $\%$ & Count & $\%$ \\
\hline Platelet & No Thrombocytopenia & 0 & $0.0 \%$ & 11 & $100.0 \%$ \\
\hline \multirow[t]{3}{*}{ Count } & Mild Thrombocytopenia & 0 & $0.0 \%$ & 5 & $100.0 \%$ \\
\hline & Moderate Thrombocytopenia & 10 & $62.5 \%$ & 6 & $37.5 \%$ \\
\hline & Severe Thrombocytopenia & 17 & $94.4 \%$ & 1 & $5.6 \%$ \\
\hline
\end{tabular}

Table 3: Comparison of Mean Platelet count and duration of Hospital stay with respect to Vitamin B12 levels

\begin{tabular}{|c|c|c|c|c|c|c|c|}
\hline & \multicolumn{6}{|c|}{ Vitamin B12 pg/ml } & \multirow[t]{3}{*}{$P$ value } \\
\hline & \multicolumn{3}{|c|}{$\begin{array}{c}\text { Vitamin B12 deficiency } \\
(<190 \mathrm{pg} / \mathrm{ml})\end{array}$} & \multicolumn{3}{|c|}{$\begin{array}{c}\text { Normal Vitamin B12 } \\
(190 \mathrm{pg} / \mathrm{ml} \text { to } 950 \mathrm{pg} / \mathrm{ml})\end{array}$} & \\
\hline & Mean & SD & Median & Mean & SD & Median & \\
\hline Platelet Count & 43037.0 & 27732.9 & 33000 & 164434.8 & 92198.8 & 150000 & $<0.001^{*}$ \\
\hline Platelet Transfusion RDP & 6.3 & 2.3 & 6 & - & - & - & - \\
\hline Hospital Stay & 8.3 & 3.1 & 7 & 3.4 & .7 & 3 & $<0.001^{*}$ \\
\hline
\end{tabular}

\begin{tabular}{|c|c|c|c|c|c|c|c|c|c|c|}
\hline & & \multicolumn{3}{|c|}{ Vitamin B12 pg/ml } & \multicolumn{3}{|c|}{ Platelet Transfusion RDP } & \multicolumn{3}{|c|}{ Hospital Stay } \\
\hline & & Mean & SD & Median & Mean & SD & Median & Mean & SD & Median \\
\hline \multirow[t]{5}{*}{ Platelet Count } & No Thrombocytopenia & 373.2 & 133.9 & 352 & . & . & . & 3.1 & .3 & 3 \\
\hline & Mild Thrombocytopenia & 329.0 & 110.4 & 298 & & . & . & 3.2 & .4 & 3 \\
\hline & $\begin{array}{l}\text { Moderate } \\
\text { Thrombocytopenia }\end{array}$ & 174.8 & 91.3 & 166 & 4.7 & 1.0 & 4 & 5.3 & 1.7 & 6 \\
\hline & $\begin{array}{l}\text { Severe } \\
\text { Thrombocytopenia }\end{array}$ & 107.2 & 108.4 & 76 & 6.9 & 2.4 & 6 & 9.3 & 3.3 & 9 \\
\hline & $P$ value & \multicolumn{3}{|c|}{$<0.001^{*}$} & \multicolumn{3}{|c|}{$0.045^{\star}$} & \multicolumn{3}{|c|}{$<0.001^{*}$} \\
\hline
\end{tabular}

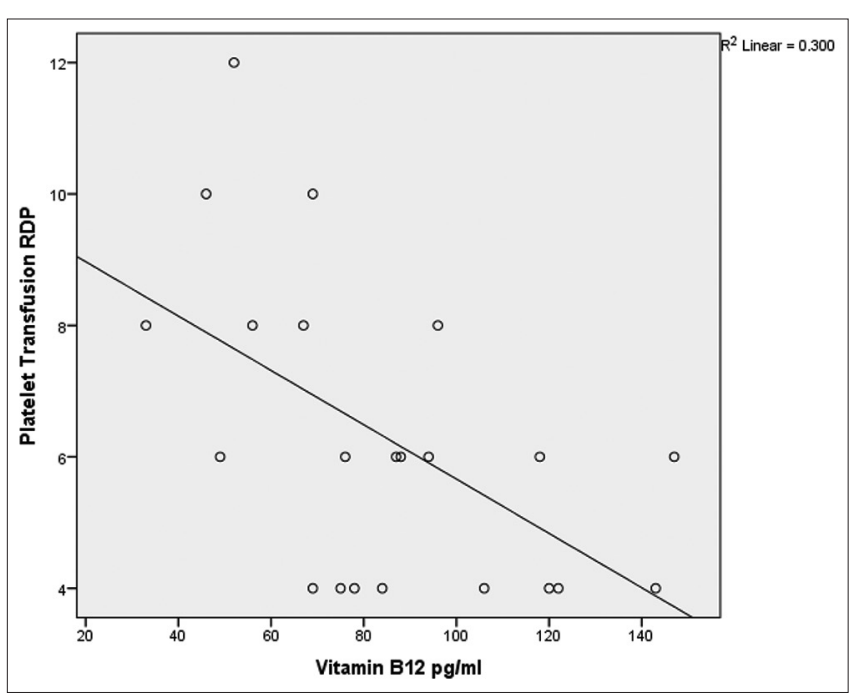

Figure 3: Scatter Plot showing Negative correlation between Vitamin B12 and Platelet Transfusion

by bleeding manifestations. A study done by Neeraja et al., showed fever was the most common presenting complaint. ${ }^{17}$ Most common bleeding manifestation was bleeding gums. In our study, $48 \%$ patients had bleeding manifestations.
Bleeding manifestations were noted in $21 \%$ of patients in the study conducted by Laul et al..$^{18}$ In our study, $16 \%$ of the patient had polyserositis. A study conducted by Senthamarai et al., showed $21 \%$ of the patient had polyserositis. ${ }^{19} \mathrm{~A}$ study done by Tak et al., showed 32.5\% patients had Vitamin B12 deficiency in dengue patients. ${ }^{20}$ In our study, $87.5 \%$ patients had Vitamin B12 deficiency less than 190pg/dl, which was statistically significant.

In our study among dengue patients with normal platelet count and mild thrombocytopenia, had normal Vitamin B12 levels. Among those with moderate thrombocytopenia, $62.5 \%$ patients had Vitamin B12 deficiency and 37.5\% patients had normal Vitamin B12 levels and among those with severe thrombocytopenia, 94.4\% had Vitamin B12 deficiency and 5.6\% had normal Vitamin B12 levels. Mean Vitamin B12 was significantly lower among those with severe thrombocytopenia. Similarly there was significant difference in mean Platelet transfusion and duration of hospital stay with respect to Severity of Platelet count. Patients with decrease in B12 levels there was increase in need of platelet transfusion and increased duration of hospital and vice versa. 


\section{CONCLUSION}

Dengue fever patients with Vitamin B12 deficiency had moderate to severe thrombocytopenia and more bleeding manifestations. Those patients required more platelet transfusion and increased duration of hospital stay. So serum Vitamin B12 levels can be tested in dengue patients with severe thrombocytopenia. Supplementation of Vitamin B12 in those patients may improve the platelet count, may decrease the bleeding manifestations and platelet transfusion. It may also reduce the duration of hospital stay. Large number of studies may require for confirming it.

\section{ACKNOWLEDGEMENT}

The authors take the opportunity to thank the Department of General Medicine for their whole hearted support for this study

\section{REFERENCES}

1. World Health Organization. Dengue and severe dengue. 2020 June 23. Available at: https://www.who.int.Newsroom fact sheets

2. Jesse J, Lionel G, Maria J, Gabriela B, Yolanda T, James S, et al. Viremia and Clinical Presentation in Nicaraguan Patients Infected With Zika Virus, Chikungunya Virus, and Dengue Virus. Clinical Infectious Diseases, 2016. 63(12): p. 1584-1590. https://doi.org/10.1093/cid/ciw589

3. Halstead SB. Pathogenesis of dengue: Challenges to molecular biology science.1988;239:476-481.

https://doi.org/10.1126/science.239.4839.476

4. Kurane I. Dengue hemorrhagic fever with special emphasis on immunopathogenesis. Comp Immunol Microbiol Infect Dis. 2007; 30:329-340.

https://doi.org/10.1016/j.cimid.2007.05.010

5. Thomas EA, John $M$ and Bhatia A. Muco-Cutaneous manifestations of dengue viral infection in Punjab. Int J Dermatol. 2007; 46:715-719.

https://doi.org/10.1111/j.1365-4632.2007.03298.x

6. Arshad I, Malik FA, Hussain A and Shah SA. Dengue fever: Clinico-pathologic correlations and their association with poor outcome. Professional Med J. 2011; 18:57-63.

7. Wu SJ, Grouard-Vigel G, Sun W, Mascola JR, Brachel E, Putvatana R, et al. Human skin langerhans cells are targets of dengue virus infection. Nat Med. 2000; 6:816-820. https://doi.org/10.1038/77553

8. Guzman MG and Kouri G. Dengue and dengue hemorrhagic fever in the Americas: Lessons and challenges. J Clin Virol. 2003; 27:1-13.

https://doi.org/10.1016/S1386-6532(03)00010-6

9. Revised and Expanded ed. New Delhi: WHO; 2011. World Health Organization. Comprehensive Guidelines for Prevention and Control of Dengue and Dengue Haemorrhagic Fever.

10. Horstick O, Martinez E, Guzman MG, Martin JL and Ranzinger SR. WHO dengue case classification 2009 and its usefulness in practice: an expert consensus in the Americas. Pathog Glob Health. 2015 Feb; 109(1): 19-25 https://doi.org/10.1179/2047773215Y.0000000003

11. World Health Organization: Comprehensive guidelines for prevention and control of dengue and dengue haemorrhagic fever. Revised and expanded edition. WHO, New Delhi; 2011.

12. Ahmed FU, Mahmood CB, Sharma JD, Hoque SM, Zaman R and Hasan $\mathrm{MH}$. Dengue fever and dengue haemorrhagic fever in chidren the 2000 outbreak in Chittatong, Bangladesh. Dengue Bulletin. 2001; 25:33-39.

13. Narayanan M, Aravind MA, Thilothammal N, Prema R, Sargunam CS and Ramamurty N. Dengue fever epidemic in Chennai-a study of clinical profile and outcome. Indian Pediatr. 2002; 39:1027-1033.

14. Whitehorn J and Farrar J. Dengue. Br Med Bull. 2010; 95:161-173. https://doi.org/10.1093/bmb/ldq019

15. Chiu YC, Wu KL, Kuo CH, Hu TH, Chou YP, Chuah SK, et al. Endoscopic findings and management of dengue patients with upper gastrointestinal bleeding. Am J Trop Med Hyg. 2005; 73:441-444. https://doi.org/10.4269/ajtmh.2005.73.441

16. Andres E, Affenberger S, Zimmer J, Vinzio S, Grosu D, Pistol G, et al. Current hematological findings in cobalamin deficiency. A study of 201 consecutive patients with documented cobalamin deficiency. Clin Lab Haematol 2006; 28:50 https://doi.org/10.1111/j.1365-2257.2006.00755.x

17. Neeraja $M$, Lakshmi V, Teja VD, Umabala $P$ and Subbalakshmi MV. Serodiagnosis of dengue virus infection in patients presenting to a tertiary care hospital. Indian $\mathrm{J}$ Med Microbio. 2006;24(4):280. https://doi.org/10.4103/0255-0857.29387

18. Laul A, Laul P, Merugumala V, Pathak R, Miglani U and Saxena P. Clinical profiles of dengue infection during an outbreak in Northern India. J Tropical Med. 2016;2016. https://doi.org/10.1155/2016/5917934

19. Senthamarai A, Vijayaraja, Murugan SV, Shridharan $P$ and Anandan $\mathrm{H}$. Profile of Dengue Fever in a Tertiary Teaching Hospital. Int J Sci Stud. 2017;5(5):220-223.

20. Tak S, Chachappan G, Rathore JS, Charan SS, Bijarniya R and Lakhotia M. Severe Thrombocytopenia in Dengue Fever and Vitamin B12 Level. J Assoc Physicians India. 2018;66(9):61-63.

\footnotetext{
Author's contribution:

MTR- Concept and design of the study, prepared first draft of manuscript, Interpreted the results; JKJM- reviewed the literature and manuscript preparation; SN- Concept, coordination, review of literature and manuscript preparation; RMB- Statistically analyzed and interpreted, preparation of manuscript and revision of the manuscript.

Work attributed to:

ESI Post Graduate Institute of Medical Science and Research, Rajajinagar, Bangalore, Karnataka, India.

Orcid ID:

Dr. Mamatha TR- (D) https://orcid.org/0000-0003-2027-8141

Dr. Jeetendra Kumar- (1) https://orcid.org/0000-0002-8030-8448

Dr. Satyanarayana N- idtps://orcid.org/0000-0002-0683-372X

Dr. Rashmi MB- (1) https://orcid.org/0000-0002-8439-5606

Source of Funding: None, Conflict of Interest: None.
} 